broom symptoms, subsequent analysis of nonsymptomatic mulberries resulted in the identical edsRNAs. In Ohio, red mulberry is a host for a mycoplasma-induced disease that routinely causes a witches' broom symptom.

This is the first report of an endogenous dsRNA associated with a deciduous tree. Further work is needed provide additional information on the nature and function of these edsRNAs in mulberry.

\section{Literature Cited}

Boccardo, G., V. Lisa, E. Louisoni, and R.G. Milne. 1987. Cryptic plant viruses. Adv. Virus Res. 32:171-214.

Gooding Jr., G.V. and T.T. Hebert. 1967. A simple technique for purifi- cation of tobacco mosaic virus in large quantities. Phytopathology $57: 1285$.

Nameth, S.T. and J.A. Dodds. 1985. Double-stranded RNAs detected in cucurbit varieties not inoculated with viruses. Phytopathology 75:1293. (Abstr.)

Stone, O.M. and M. Hollings. 1973. Some properties of pelargonium flower-break virus. Ann. Applied Biol. 75:15-23.

Valverde, R.A. and J.F. Fontenot. 1991. Variation in double-stranded ribonucleic acid among pepper cultivars. J. Amer. Soc. Hort. Sci. 116:903-905.

Valverde, R.A., S.T. Nameth, O. Abdalla, O. Al-Musa, P. Desjardins, and A. Dodds. 1990. Indigenous double-stranded RNA from pepper (Capsicum апnиит). Plant Sci. 67:195-201. 
cheesecloth, and $9 \mathrm{ml} \mathrm{n}$-butanol per $100 \mathrm{ml}$ of extract was added. The extract was shaken for $5 \mathrm{~min}$ and stored at $2 \mathrm{C}$ for $24 \mathrm{~h}$. Concentration of the virus was achieved by two cycles of differential centrifugation: $12,000 \times g$ for $25 \mathrm{~min}$ and then $100,000 \times g$ for $2 \mathrm{~h}$. The resulting pellet was resuspended in $2 \mathrm{ml} 0.03 \mathrm{M}$ phosphate buffer. The clarified virus extract was layered over a sucrose density gradient (10\% to $60 \%$ ) and centrifuged at $27,000 \mathrm{rpm}$ for $3 \mathrm{~h}$ (Rotor SW 28, model L8M, S/N 7K537 ultracentrifuge; Beckman Instruments, Palo Alto, Calif.). The resulting suspension was prepared for observation by electron microscopy.

Electron microscopy. For leaf dip preparations, a drop $(10 \mu \mathrm{l})$ of $2 \%$ potassium phosphotungstate (PPT) at $\mathrm{pH} 6.5$ was placed on a carbon-coated copper electron microscope grid, and a triangular piece of mulberry leaf tissue (dsRNA positive) was rapidly dipped in and out of the drop of stain. After 3 min, excess stain was blotted with filter paper. The grid was examined using transmission electron microscopy (model E.M. 300; Phillips, Eindhoven, Netherlands).

For purified virus preparations, a drop of the purified preparation was placed on the carbon-coated copper grid and left for $5 \mathrm{~min}$. The preparation was blotted with filter paper and a drop of $2 \%$ PPT was placed on the grid and allowed to remain for $5 \mathrm{~min}$. The stain was drained off and the grid was examined as above.

Enzyme treatment. Purified mulberry edsRNA was resuspended in $250 \mu \mathrm{l}$ of RNase A (type I; Sigma Chemical Co., St. Louis) and DNase I (Sigma) at a final concentration of $25 \mu \mathrm{g} \cdot \mathrm{ml}^{-1}$. The preparations were incubated at $27 \mathrm{C}$ for $30 \mathrm{~min}$. RNase digestion was carried out in either a $1 \mathrm{x}$ (high salt) or a $0.1 \mathrm{x}$ (low salt) solution of SSC (SPELL) containing $0.15 \mathrm{M} \mathrm{NaCl}, 0.005 \mathrm{M} \mathrm{MgCl}_{2}$, and $0.015 \mathrm{M}$ sodium citrate ( $\mathrm{pH} 7$ ). Each sample was extracted with two volumes of STE-saturated phenol and one volume of $24 \mathrm{CHCl}_{3}: 1$ isopentanol on ice for $20 \mathrm{~min}$ and centrifuged for $15 \mathrm{~min}$ at $6500 \times$ $g$. The aqueous phase was collected and precipitated in two to three volumes of $95 \%$ cold ethanol and a 1/20 volume of 3 m sodium acetate. This solution was incubated at $-20 \mathrm{C}$ for $4 \mathrm{~h}$. The solution was centrifuged at $13,000 \times g$ for $20 \mathrm{~min}$. The resulting pellet was resuspended in buffer and prepared for electrophoresis analysis.

\section{Results and Discussion}

dsRNA analysis of apparently healthy leaf tissue sampled at random from 20 red mulberry yielded four distinct dsRNA banding profiles (Fig. 1). dsRNA type 1 contained three dsRNA bands

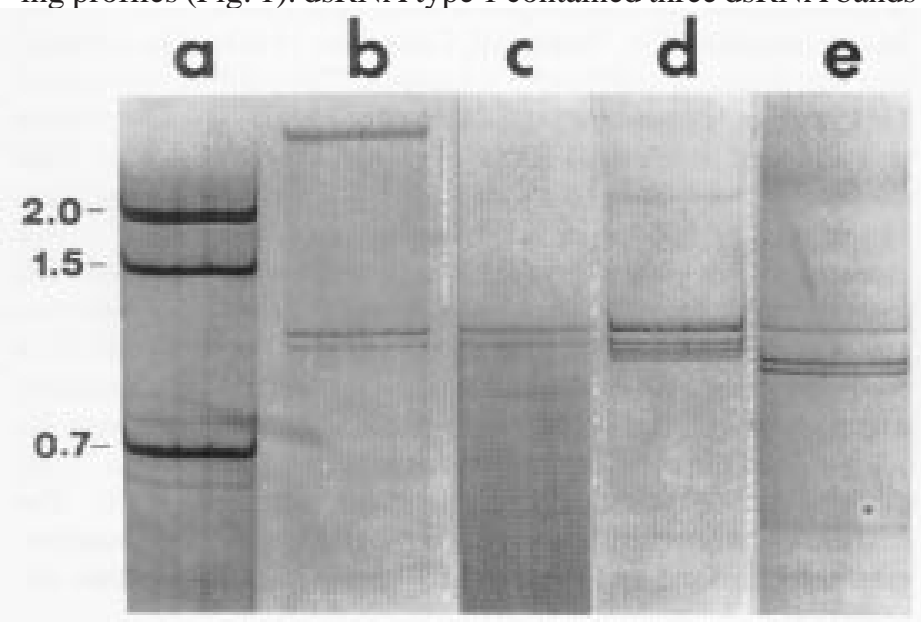

Fig. 1. Polyacrylamide gel (5\%) electrophoresis of endogenous dsRNAs (edsRNAs) extracted from mulberry. (a) dsRNA molecular weight markers $\left(2.0,1.5\right.$, and $\left.0.7 \times 10^{6}\right)$; (b) edsRNA type 1; (c) edsRNA type 2; (d) edsRNA type 3; (e) edsRNA type 4. with approximate MWs of $12.0,1.0$, and $0.9 \times 10^{6}$, respectively. dsRNA type 2 contained two dsRNA bands with MWs of 1.0 and $0.9 \times 10^{6}$. dsRNA type 3 contained four bands with MWs of 1.0 , $0.9,0.89$, and $0.88 \times 10^{6}$. dsRNA type 4 contained three bands with MWs of $1.0,0.88$, and $0.87 \times 10^{6}$. Three of the 20 mulberry samples analyzed did not contain detectable amounts of dsRNA. Virus purification methods performed on mulberry leaf tissue positive for dsRNA did not produce detectable virus particles (spherical or rod shaped) when purified preparations were observed using electron microscopy. Results of enzyme treatment using RNase A and DNase I indicated that purified mulberry dsRNA was resistant to digestion with DNase I and RNase A in high salt. Purified mulberry dsRNA was susceptible to RNase A digestion in low salt.

Results indicate that symptomless red mulberries contain a variety of high-MW dsRNAs similar to those observed in other plant species (Nameth and Dodds, 1985,

Valverde et al., 1990). Like those, mulberry edsRNA could not be transmitted to mulberry or other hosts via mechanical or graft transmission (data not shown). Since these dsRNAs were resistant to DNase 1 and RNase A digestion in high salt and susceptible to RNase A digestion in low salt, one could conclude that RNAs isolated from mulberry are indeed double-stranded. When compared to other endogenous dsRNAs associated with other hosts, the mulberry edsRNA type 1 was similar but not identical (Fig. 2). The mulberry edsRNA type $112.0 \times 10^{6} \mathrm{MW}$ band appeared to co-electrophorese with pepper and cantaloupe (cantaloupe data not shown) and the type $11.0 \times 10^{6} \mathrm{MW}$ band appeared to co-electrophorese with watermelon (Fig. 2). Although these edsRNAs seem to have similar MWs, experiments need to be conducted on possible sequence homology. Previous work has indicated no shared sequence homology among edsRNA isolated from different host species (Valverde et al., 1990). Also, mulberry edsRNA types 1 to 4 seem to be somewhat similar to those found in various other pepper cultivars (Valverde and Fontenot, 1991). Until identical electrophoresis studies are performed with these other cultivars, one can only speculate as to their relatedness. Since no obvious virus particles or symptoms could be associated with these dsRNAs, it would suggest that these dsRNAs are endogenous. It could also suggest the possibility of a cryptic virus (Boccardo et al., 1987). Additional work is needed to determine if the edsRNA isolated from mulberry indicates a cryptic virus infection. Although the original mulberry expressed witches'

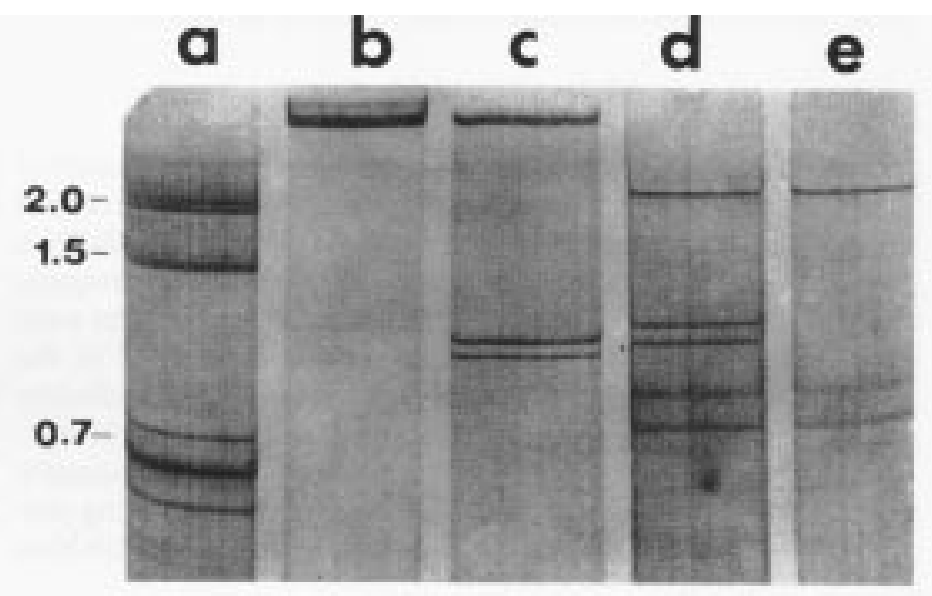

Fig. 2. Polyacrylamide gel (5\%) electrophoresis of endogenous dsRNAs (edsRNAs) extracted from a variety of hosts. (a) dsRNA molecular weight markers $(2.0,1.5$, and 0.7 $\left.\times 10^{6}\right)$; (b) edsRNA from 'Yolo Wonder' pepper $\left(12.0 \times 10^{6}\right)$; (c) mulberry edsRNA type 1; (d) edsRNA from 'Sugar Baby' watermelon; (e) edsRNA 'Early Prolific' squash. 


\title{
Identification and Partial Characterization of Endogenous Double-stranded Ribonucleic Acid in Mulberry
}

\author{
S.T. Nameth and S.L. Cheng ${ }^{1}$ \\ Department of Plant Pathology, The Ohio Agricultural Research and Development Center, The Ohio State \\ University, Columbus, $\mathrm{OH} 43210$
}

Additional index words. mulberry, endogenous double-stranded RNA

\begin{abstract}
Double-stranded ribonucleic acid (dsRNA) analysis of apparently healthy red mulberry (Morus rubra L.) yielded four distinct dsRNA banding profiles. dsRNA type 1 contained three dsRNA bands with approximate molecular weights (MWs) of 12.0, 1.0, and $0.9 \times 10^{6}$, respectively. dsRNA type 2 contained two dsRNA bands with MWs of 1.0 and $0.9 \times 10^{6}$. dsRNA type 3 contained four dsRNA bands with MWs of $1.0,0.9,0.89$, and $0.88 \times 10^{6}$. dsRNA type 4 contained three dsRNA bands with MWs of $1.0,0.88$, and $0.87 \times 10^{6}$. No virus particles were associated with any of the samples analyzed. All four types of dsRNA were resistant to DNase I and RNase A in high salt and susceptible to RNase A in low salt. Mulberry dsRNAs were somewhat similar to endogenous dsRNAs (edsRNA) associated with other hosts. This is the first report of edsRNA associated with a deciduous tree.
\end{abstract}

Mulberries (Morus spp.) are small trees or shrubs common to the temperate and subtropical regions of the northern hemisphere. One indigenous species, red mulberry (Morus rubra), is widely distributed throughout Ohio.

In Spring 1990, a red mulberry with witches' broom symptoms was submitted for disease analysis to the Plant and Pest Diagnostic Clinic, The Ohio State Univ. Subsequent tests on leaf tissue indicated the presence of double-stranded ribonucleic acids (dsRNAs) similar to those found in other plant species (Nameth and Dodds, 1985; Valverde et al., 1990). These dsRNAs, termed endogenous double-stranded ribonucleic acid (edsRNA), have been previously reported in cantaloupe (Cucumis melo L.), watermelon [Citrullus lanatus (Thunb.) Matsum and Nakai], squash (Cucurbita pepo L.), pepper (Capsicum annuum L.), and tomato (Lycopersicon esculentum Mill.) (Nameth and Dodds, 1985, Valverde et al., 1990). These high molecular weight (MW) dsRNAs were not associated with any virus particle or any virus-induced symptoms on the host plant.

Since edsRNA has never been isolated from any deciduous tree, a study was conducted to determine if the dsRNA associated with red mulberry was indeed endogenous and also to determine possible types of edsRNAs found in red mulberry in Ohio.

\section{Materials and Methods}

dsRNA analysis. Unless otherwise noted, leaf tissue was sampled at random from apparently healthy red mulberry growing in central Ohio. One sample was taken from western Pennsylvania. dsRNA from 'Hales Best Jumbo' cantaloupe, 'Early Prolific' Iroquois squash, and 'Crimson Sweet' and 'Sugar Baby' watermelon were extracted from leaf tissue of plants grown from seed in the greenhouse. edsRNA from 'Yolo Wonder' pepper was supplied by Rodrigo Valverde, Louisiana State Univ., Baton Rouge. Viral-associated dsRNAs were extracted from $7.0 \mathrm{~g}$ of apparently healthy mulberry, cantaloupe, squash, and watermelon using procedures previously described by Valverde et al. (1990). dsRNAs

Received for publication 14 June 1993. Accepted for publication 27 Dec. 1993. The cost of publishing this paper was defrayed in part by the payment of page charges. Under postal regulations, this paper therefore must be hereby marked advertisement solely to indicate this fact.

${ }^{1}$ Present address: Dept. of Plant Pathology, Univ. of Illinois, Urbana, IL 61801. were extracted from plant tissue by adding $0.5 \mathrm{ml} 2$-mercaptoethanol per $7.0 \mathrm{~g}$ tissue and purified by two cycles of cellulose powder column chromatography. dsRNAs retained by the column in STE $[0.1 \mathrm{M} \mathrm{NaCl}, 0.05 \mathrm{M}$ tris- $\mathrm{HCl}$ and $0.001 \mathrm{M}$ ethylediamine tetracetic acid (EDTA), pH 7.0] buffered ethanol (16\% w/v) and subsequently eluted in ethanol-free STE were precipitated with three volumes of $95 \%$ ethanol and resuspended in $300 \mu \mathrm{l}$ of electrophoresis buffer. dsRNA samples were analyzed with $5 \%$ polyacrylamide gels as described previously (Valverde et al., 1990). Aliquots of $30 \mu \mathrm{l}$ were loaded on $5 \%$ polyacrylamide gels in a vertical slab apparatus. Electrophoresis was at a constant voltage of $110 \mathrm{~V}$ for $2 \mathrm{~h}$. Gels were stained with silver and photographed.

Virus purification. To determine if the dsRNA identified in red mulberry was associated with a virus particle, virus purification was conducted on mulberry leaf tissue, which tested positive for dsRNA. Two plant virus purification strategies were used: one for a rod-shaped virus (Gooding and Hebert, 1967) and one for a spherical virus (Stone and Hollings, 1973). To detect a possible rod-shaped virus, $50 \mathrm{~g}$ of mulberry leaves was blended with $100 \mathrm{ml}$ $0.2 \mathrm{M}$ potassium phosphate buffer ( $\mathrm{pH}$ 7.2) and $1 \mathrm{ml}$ 2-mercaptoethanol. The extract was filtered through several layers of cheesecloth and centrifuged at $8000 \mathrm{rpm}$ (Sorvall RC2-B; Du Pont Instruments Co., Newtown, Conn.) for $15 \mathrm{~min}$. The supernatant was adjusted to $8 \%$ (v/v) n-butanol. The solution was stirred for $15 \mathrm{~min}$ and centrifuged at $8000 \mathrm{rpm}$ for $15 \mathrm{~min}$. The supernatant was adjusted to 4\% PEG 8000 (w/v) and $0.6 \mathrm{~g} \mathrm{NaCl}(\mathrm{w} / \mathrm{v})$. This suspension was allowed to stand for 2 to $4 \mathrm{~h}$ at $4 \mathrm{C}$ and was centrifuged at $8000 \mathrm{rpm}$ for $15 \mathrm{~min}$. The resulting pellet was resuspended in 60 to $70 \mathrm{ml}$ double-distilled water, resuspended, and centrifuged for $10 \mathrm{~min}$ at $10,000 \mathrm{rpm}$. The volume of supernatant was measured and adjusted to 4\% PEG $8000(\mathrm{w} / \mathrm{v})$ and $0.6 \mathrm{~g}$ $\mathrm{NaCl}(\mathrm{w} / \mathrm{v})$ per $100 \mathrm{ml}$ of supernatant. This suspension was stirred overnight at $4 \mathrm{C}$. The suspension was centrifuged at $8000 \mathrm{rpm}$ for $15 \mathrm{~min}$, and the resulting pellet was resuspended in 12 to $15 \mathrm{ml}$ double-distilled water and left to stand overnight at $4 \mathrm{C}$. The suspension was centrifuged at $8000 \mathrm{rpm}$ for $15 \mathrm{~min}$. The supernatant was collected and prepared for observation by electron microscopy.

To detect a possible spherical virus, mulberry leaves were homogenized in 2 to $4 \mathrm{ml}$ per g $0.05 \mathrm{M}$ phosphate buffer, $\mathrm{pH} 7.6$, containing $0.1 \%$ thioglycollic acid. The extract was filtered through 